\title{
Antifungal activity of cinnamaldehyde and eugenol congeners against wood-rot fungi
}

\author{
Sen-Sung Cheng ${ }^{\text {a }}$, Ju-Yun Liu ${ }^{\mathrm{b}}$, Ed-Haun Chang ${ }^{\mathrm{c}}$, Shang-Tzen Chang ${ }^{\mathrm{b}, *}$ \\ ${ }^{a}$ The Experimental Forest, National Taiwan University, Nan-Tou 557, Taiwan \\ ${ }^{\mathrm{b}}$ School of Forestry and Resource Conservation, National Taiwan University, Taipei 106, Taiwan \\ ${ }^{\mathrm{c}}$ Mackay Medicine, Nursing and Management College, Taipei 112, Taiwan
}

Received 24 July 2007; received in revised form 6 September 2007; accepted 7 September 2007

Available online 22 October 2007

\begin{abstract}
In this study, the antifungal activities of cinnamaldehyde and eugenol congeners against white-rot fungus Lenzites betulina and brown-rot fungus Laetiporus sulphureus were evaluated and the relationships between the antifungal activity and the chemical structures were also examined. Results from antifungal tests revealed that cinnamaldehyde, $\alpha$-methyl cinnamaldehyde, $(E)$-2-methylcinnamic acid, eugenol and isoeugenol exhibited strong antifungal activity against all fungi tested. Results derived from the chemical structure-antifungal activity relationship study suggested that compounds with an aldehyde group or an acid group, a conjugated double bond and a length of $\mathrm{CH}$ chain outside the ring affect their antifungal properties. Furthermore, the presence of the methyl moiety in the ortho position may have a considerable influence on the inhibitory action against $L$. betulina and $L$. sulphureus. In addition, the lipophilicity may play, in part, a crucial role in determining the toxicity of phenylpropenes.
\end{abstract}

(C) 2007 Elsevier Ltd. All rights reserved.

Keywords: Antifungal activity; Cinnamaldehyde; Eugenol; Laetiporus sulphureus; Lenzites betulina

\section{Introduction}

Biodegradation of wood by fungi is a serious problem for both wooden structures and forest management. Basidiomycete fungi of the genera Trametes, Lenzites, and Laetiporus are recognized worldwide as major wood decay fungi (Wu et al., 2005). Failure to control them can result in tremendous economic and resource losses. To extend the service life, wood products are therefore often treated with preservatives such as creosote, pentachlorophenol and inorganic arsenicals. However, these agents will be phased out in the near future due to their potential adverse impact on the environment. Therefore, the search for safer phytochemicals with lower environmental and mammalian

\footnotetext{
* Corresponding author. Tel.: +88623366 4626; fax: +886223654520. E-mail address: peter@ntu.edu.tw (S.-T. Chang).
}

toxicity is a major concern and imperative (Schultz and Nicholas, 2000; Wedge et al., 2000).

Various plant materials are believed to have antifungal property and many essential oils have been reported to have antifungal activities. Cinnamaldehyde, a major constituent of cinnamon essential oils, occurs naturally in the bark and leaves of cinnamon trees of the genus Cinnamomum. It has been proven to have strong antifungal activities against a wide variety of wood decay fungi (Wang et al., 2005a; Cheng et al., 2006). Eugenol is a major phenolic component of clove oil and has been demonstrated as an excellent fungicide against wood decay fungi (Wang et al., 2005a). Moreover, several naturally occurring compounds such as $\alpha$-cadinol (Chang et al., 1999), T-muurolol, T-cadinol, $\gamma$-cadinene (Kondo and Imamura, 1986; Chang et al., 2000), cryptomeridiol (Morita et al., 1997), chamaecynone (Wang et al., 2005b), and ferruginol (Rudman, 1965) have been reported to be effective against wood decay fungi. To the best of our knowledge, no antifungal 
activities of the congeners of both cinnamaldehyde and eugenol have been reported. Therefore, this paper describes a laboratory study to examine the toxicity of the congeners of both cinnamaldehyde and eugenol against wood decay fungi and their structure-activity relationships were addressed.

\section{Methods}

\subsection{Fungal strains}

The wood decay fungi were obtained from the Bioresource Collection and Research Center (BCRC) of the Food Industry Research and Development Institute (Taiwan). The fungal strains used in experiments were as follows: one white-rot fungi [Lenzites betulina (BCRC 35296)] and one brown-rot fungi [Laetiporus sulphureus (BCRC 35305)].

\subsection{Chemicals}

Benzaldehyde (1), 4-hydroxybenzaldehyde (2), cinnamaldehyde (3), benzenepropanal $(4),(E)$-cinnamic acid (6), cinnamyl alcohol (7), methyl cinnamate (9), cinnamyl acetate $(\mathbf{1 0}),(E)$-2-methylcinnamic acid (11), $(E)$-3-methylcinnamic acid (12), (E)-4-methylcinnamic acid (13), $(E)$-2hydroxycinnamic acid (14), (E)-3-hydroxycinnamic acid (15), (E)-4-hydroxycinnamic acid (16), and eugenol (17) were purchased from Acros (Belgium). 2-Methyl-3-phenyl-2-propen-1-ol (8) was purchased from Sigma Chemical Co. (USA). $\alpha$-Methyl cinnamaldehyde (5), acetyleugenol (18), isoeugenol (19), and methyleugenol (20) were purchased from TCI (Japan). Commercial fungicide didecyl dimethyl ammonium chloride (DDAC) was used as a positive control.

\subsection{Antifungal assays}

One white-rot fungus, L. betulina (CCRC 35296) and one brown-rot fungus, L. sulphureus (CCRC 35305), were used in this experiment. The method of Chang et al. (1999) was employed for antifungal evaluation of cinnamaldehyde and eugenol congeners. Briefly, 100, 50, 25, and $12.5 \mu \mathrm{g} / \mathrm{ml}$ of compounds were added to sterilize potato dextrose agar (PDA) in 9-cm Petri dishes. After transferring the mycelium of two fungi strains, the testing dishes were incubated at $26 \pm 2{ }^{\circ} \mathrm{C}, 70 \%$ relative humidity. When the mycelium of fungi reached the edges of control dishes (without compounds added) after approximately 10-14 days, the antifungal indices were calculated. Each test was repeated four times, and the data averaged. The $\mathrm{IC}_{50}$ values (the concentration in $\mu \mathrm{g} / \mathrm{ml}$ that inhibited $50 \%$ of the mycelium of fungi growth) were calculated by probit analysis. Didecyl dimethyl ammonium chloride (DDAC), a commercially available fungicide, was used as a reference compound. The formula of antifungal indices was shown as follows:
Antifungal index $(\%)=\left(1-D_{\mathrm{a}} / D_{\mathrm{b}}\right) \times 100$

where $D_{\mathrm{a}}$ is the diameter of the growth zone in the experimental dish $(\mathrm{cm})$ and $D_{\mathrm{b}}$ is the diameter of the growth zone in the control dish $(\mathrm{cm})$.

\subsection{Statistical analyses}

All results were expressed as mean $\pm \mathrm{SD}(n=4)$. The significance of difference was calculated using SAS Scheffe's test, and results with $P<0.05$ were considered to be statistically significant.

\section{Results and discussion}

\subsection{Antifungal activity of cinnamaldehyde and its congeners}

In our previous studies, cinnamaldehyde (3) is the strongest antifungal compound in the leaf essential oils of Cinnamomum osmophloeum (Wang et al., 2005a; Cheng et al., 2006). Thus, to examine the structure-activity relationships of cinnamaldehyde, 15 compounds whose chemical structures are similar to cinnamaldehyde were selected for this study. These compounds are benzaldehyde (1), 4-hydroxybenzaldehyde (2), benzenepropanal (4), $\alpha$-methyl cinnamaldehyde (5), (E)-cinnamic acid (6), cinnamyl alcohol (7), 2-methyl-3-phenyl-2-propen-1-ol (8), methyl cinnamate (9), cinnamyl acetate (10), (E)-2-methylcinnamic acid (11), (E)-3-methylcinnamic acid (12), (E)-4-methylcinnamic acid (13), (E)-2-hydroxy-cinnamic acid (14), $(E)$-3-hydroxycinnamic acid (15), and $(E)$-4-hydroxylcinnamic acid (16).

Fig. 1 presents the results of antifungal activity of these compounds against white-rot fungus $L$. betulina and

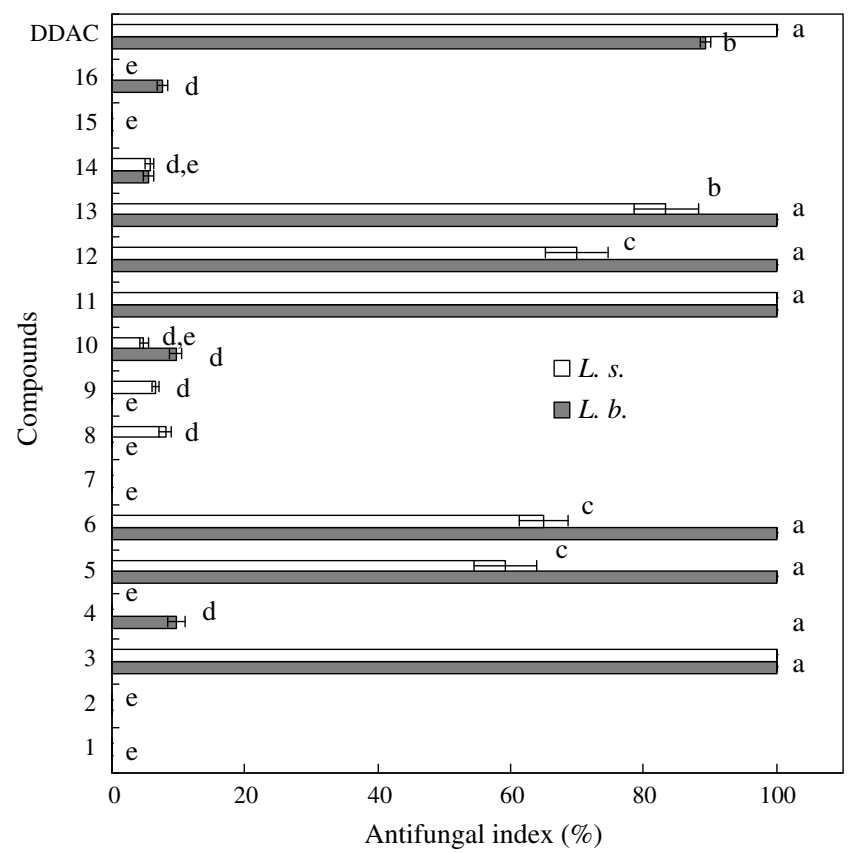

Fig. 1. Antifungal activities of cinnamaldehyde and its congeners against white-rot fungus $L$. betulina and brown-rot fungus $L$. sulphureus (concentration used is $100 \mu \mathrm{g} / \mathrm{ml}$ ). 
brown-rot fungus L. sulphureus at the concentration of $100 \mu \mathrm{g} / \mathrm{ml}$. Results from antifungal tests revealed that compounds 3, 5, 6, and 11-13 were the most active against $L$. sulphureus amongst the 16 compounds tested, with antifungal indices higher than 59.3\%; while compounds 1-2, 4, 7-10, and 14-16 were the least active, with antifungal indices lower than $8.1 \%$. Furthermore, compounds 3 and 11 inhibited completely the growth of $L$. sulphureus at the concentration of $100 \mu \mathrm{g} / \mathrm{ml}$. Similarly, compounds 3, 5, 6, and 11-13 also exhibited strong antifungal action with antifungal indices of $100.0 \%$ against $L$. betulina at the concentration of $100 \mu \mathrm{g} / \mathrm{ml}$, while compounds $\mathbf{1 - 2}, \mathbf{4}, \mathbf{7 - 1 0}$, and 14-16 did not express antifungal activities at the same concentration, with antifungal indices lower than $9.7 \%$.

$\mathrm{IC}_{50}$ values of the 16 compounds against $L$. betulina and L. sulphureus were further determined and the results obtained are shown in Table 1 . In terms of the $\mathrm{IC}_{50}$ values, the antifungal activity of compounds 3, 5, 6, and 1113 against $L$. sulphureus is ranked as cinnamaldehyde (3) $(35.3 \mu \mathrm{g} / \mathrm{ml})>(E)$-2-methylcinnamic acid (11) $(39.2 \mu \mathrm{g} /$ $\mathrm{ml})>(E)$-4-methylcinnamic acid (13) $(58.5 \mu \mathrm{g} / \mathrm{ml})>(E)-$ 3-methylcinnamic acid (12) $(66.7 \mu \mathrm{g} / \mathrm{ml})>\alpha$-methyl cinnamaldehyde (5) $(83.5 \mu \mathrm{g} / \mathrm{ml})>(E)$-cinnamic acid (6) $(87.4 \mu \mathrm{g} / \mathrm{ml})$. On the other hand, the order of $\mathrm{IC}_{50}$ values against $L$. betulina are $\alpha$-methyl cinnamaldehyde (5) $(22.0 \mu \mathrm{g} / \mathrm{ml})>(E)$-2-methylcinnamic acid (11) $(47.2 \mu \mathrm{g} /$ $\mathrm{ml})>(E)$-3-methylcinnamic acid (12) $(49.3 \mu \mathrm{g} / \mathrm{ml})>(E)-$ cinnamic acid (6) $(55.8 \mu \mathrm{g} / \mathrm{ml})>(E)$-4-methylcinnamic acid (13) $(58.2 \mu \mathrm{g} / \mathrm{ml})>$ cinnamaldehyde $(3)(58.9 \mu \mathrm{g} / \mathrm{ml})$. These results indicated that having an aldehyde group or an acid group, a conjugated double bond and a length of $\mathrm{CH}$ chain outside the ring, i.e. cinnamaldehyde or $\alpha$ methyl cinnamaldehyde, possesses much stronger antifungal activity. A similar observation was also noted in our previous studies on the antibacterial (Chang et al.,

Table 1

$\mathrm{IC}_{50}$ values $(\mu \mathrm{g} / \mathrm{ml})$ of cinnamaldehyde and its congeners against white-rot fungus $L$. betulina and brown-rot fungus $L$. sulphureus

\begin{tabular}{lcc}
\hline Compounds & Fungi & \\
\cline { 2 - 3 } & L. betulina & L. sulphureus \\
\hline $\mathbf{1}$ & $>100.0$ & $>100.0$ \\
$\mathbf{2}$ & $>100.0$ & $>100.0$ \\
$\mathbf{3}$ & 58.9 & 35.3 \\
$\mathbf{4}$ & $>100.0$ & $>100.0$ \\
$\mathbf{5}$ & 22.0 & 83.5 \\
$\mathbf{6}$ & 55.8 & 87.4 \\
$\mathbf{7}$ & $>100.0$ & $>100.0$ \\
$\mathbf{8}$ & $>100.0$ & $>100.0$ \\
$\mathbf{9}$ & $>100.0$ & $>100.0$ \\
$\mathbf{1 0}$ & $>100.0$ & $>100.0$ \\
$\mathbf{1 1}$ & 47.2 & 39.2 \\
$\mathbf{1 2}$ & 49.3 & 66.7 \\
$\mathbf{1 3}$ & 58.2 & 58.5 \\
$\mathbf{1 4}$ & $>100.0$ & $>100.0$ \\
$\mathbf{1 5}$ & $>100.0$ & $>100.0$ \\
$\mathbf{1 6}$ & $>100.0$ & $>100.0$ \\
DDAC & 13.7 & 1.3 \\
\hline
\end{tabular}

2001), antitermitic (Chang and Cheng, 2002), antimosquito (Cheng et al., 2004), and antifungal (Lee et al., 2005; Wang et al., 2005a) activities of C. osmophloeum. A different finding was observed in the other bioactivity assay. Kim et al. (2004) have evaluated the acaricidal activity of cinnamaldehyde and its congeners against Tyrophagus putrescentiae, their results indicated that a conjugated double bond and a length of $\mathrm{CH}$ chain outside the ring appear not to be responsible for $T$. putrescentiae toxicity. In addition, on the basis of the antifungal activity of the seven cinnamic acid derivatives, the hydroxyl group on the cinnamic acid structure has no significant influence on antifungal activity, but the presence of the methyl group in the ortho position may have a considerable influence on the inhibitory action against L. betulina and L. sulphureus (Table 1). The results differ from those reported by Kim et al. (2004), who suggested that the presence of the hydroxyl moiety in the ortho position may have a considerable influence on the $T$. putrescentiae toxicity. We assume that the discrepancy might be due to the different mechanisms involved in the inhibition of fungi and mites.

\subsection{Antifungal activity of eugenol and its congeners}

According to our previous studies (Wang et al., 2005a; Yen and Chang, 2008), eugenol has been demonstrated as an excellent fungicide against wood decay fungi. To our best knowledge, antifungal activity of the eugenol congeners against wood decay fungi has not been reported, so this property appears to be worthy of evaluation. To examine the structure-activity relationships of eugenol (17), three compounds whose chemical structures are similar to eugenol were selected for the study. These compounds were acetyleugenol (18), isoeugenol (19), and methyleugenol (20). The antifungal activities of these compounds against both white-rot fungus ( $L$. betulina) and brown-rot fungus (L. sulphureus) at the concentration of $100 \mu \mathrm{g} / \mathrm{ml}$ are shown in Fig. 2.

It was noticed that compounds $\mathbf{1 7}$ and $\mathbf{1 9}$ exhibited the strongest activity against both $L$. sulphureus and L. betulina amongst the four compounds tested. Both compounds $\mathbf{1 7}$ and 19 inhibited totally the growth of L. betulina (antifungal index $=100.0 \%$ ) at the concentration of $100 \mu \mathrm{g} /$ $\mathrm{ml}$. As for L. sulphureus, however, compound 17 (antifungal index $=90.3 \%$ ) showed a lower activity than compound 19 (antifungal index $=100.0 \%$ ). The antifungal activity of all these compounds against L. sulphureus in term of the $\mathrm{IC}_{50}$ values is ranked as isoeugenol (19) $(27.6 \mu \mathrm{g} / \mathrm{ml})>$ eugenol (17) $(62.9 \mu \mathrm{g} / \mathrm{ml})>$ acetyleugenol (18) $(>100.0 \mu \mathrm{g} / \mathrm{ml})=$ methyleugenol $(\mathbf{2 0})(>100.0 \mu \mathrm{g} / \mathrm{ml})$. On the other hand, the order of $\mathrm{IC}_{50}$ values against $L$. betulina is eugenol (17) $(36.9 \mu \mathrm{g} / \mathrm{ml})>$ isoeugenol (19) $(39.9 \mu \mathrm{g} /$ $\mathrm{ml})>$ acetyleugenol $(\mathbf{1 8})(>100.0 \mu \mathrm{g} / \mathrm{ml})=$ methyleugenol (20) $(>100.0 \mu \mathrm{g} / \mathrm{ml})$ (Table 2). These results indicated that lipophilicity may play, in part, a crucial role in determining the toxicity of phenylpropenes. 


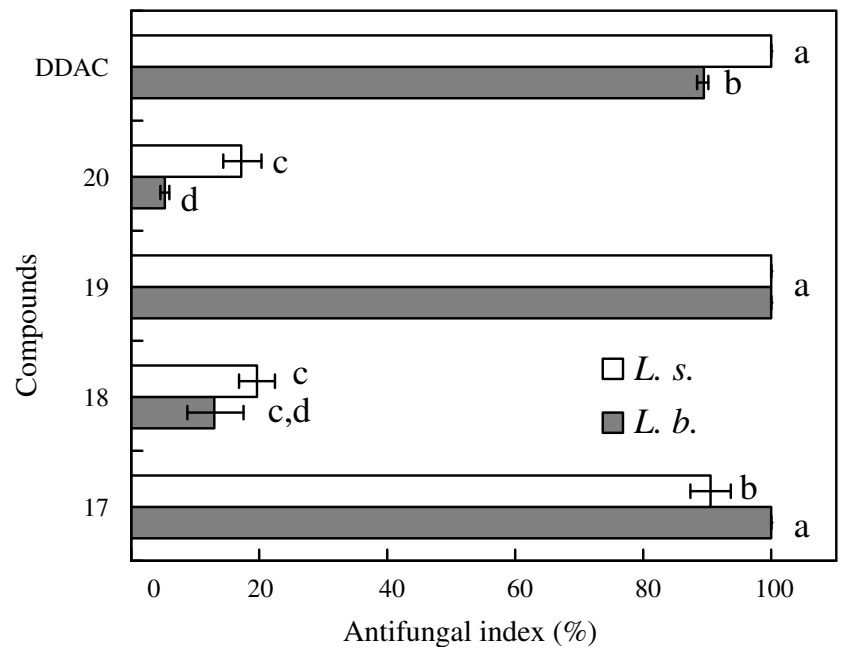

Fig. 2. Antifungal activities of eugenol and its congeners against white-rot fungus $L$. betulina and brown-rot fungus $L$. sulphureus (concentration used is $100 \mu \mathrm{g} / \mathrm{ml}$ ).

Table 2

$\mathrm{IC}_{50}$ values $(\mu \mathrm{g} / \mathrm{ml})$ of eugenol and its congeners against white-rot fungus L. betulina and brown-rot fungus $L$. sulphureus

\begin{tabular}{lcc}
\hline Compounds & Fungi & \\
\cline { 2 - 3 } & L. betulina & L. sulphureus \\
\hline $\mathbf{1 7}$ & 36.9 & 62.9 \\
$\mathbf{1 8}$ & 100.0 & $>100.0$ \\
$\mathbf{1 9}$ & 39.9 & 27.6 \\
$\mathbf{2 0}$ & $>100.0$ & $>100.0$ \\
DDAC & 13.7 & 1.3 \\
\hline
\end{tabular}

A similar finding was observed in other bioactivity assay. Kim et al. (2003) have evaluated the acaricidal activity of clove bud oil-derived eugenol and its congeners against Dermatophagoides farinae and Dermatophagoides pteronyssinus. Their results indicated that the lipophilicity of the four phenylpropenes plays a crucial role in dust mite toxicity. Wu et al. (2005) studied the structure-activity relationship between cadinane-type sesquiterpene derivatives and antifungal activity against wood decay fungi. Their findings showed that the presence of an unsaturated double bond and oxygen-containing functional groups in the compounds plays a key role in their antifungal activity, and that the stereo configuration of cadinane-type sesquiterpenes also influences their antifungal activity.

\section{Conclusions}

With regard to environmental protection, the search for environmental friendly preservatives from highly durable tree species represents one approach to achieving protection of the wood without polluting the environment. In this study, we investigated the structure-activity relationships of cinnamaldehyde and eugenol congeners against wood decay fungi, which has not been reported previously. Cinnamaldehyde, $\alpha$-methyl cinnamaldehyde, $(E)$-2-methylcin- namic acid, eugenol, and isoeugenol showed good antifungal activities against all fungi tested. Clearly, the presence of an aldehyde group or an acid group, a conjugated double bond and a length of $\mathrm{CH}$ chain outside the ring has an influence on their antifungal properties. Furthermore, the presence of the methyl group in the ortho position may have a considerable influence on the inhibitory performance against $L$. betulina and $L$. sulphureus. In addition, the lipophilicity may play, in part, a crucial role in determining the toxicity of the phenylpropenes. Thus, understanding the influence of structures of both cinnamaldehyde and eugenol congeners on their antifungal actions could be helpful in designing and developing more effective wood preservatives.

\section{Acknowledgements}

The authors thank Bioresource Collection and Research Center (BCRC) of the Food Industry Research and Development Institute (Taiwan) for providing the fungi.

\section{References}

Chang, S.T., Wang, S.Y., Wu, C.L., Su, Y.C., Kuo, Y.H., 1999 Antifungal compounds in the ethyl acetate soluble fraction of the extractives of Taiwania (Taiwania cryptomerioides Hayata) heartwood. Holzforschung 53, 487-490.

Chang, S.T., Wang, S.Y., Wu, C.L., Chen, P.F., Kuo, Y.H., 2000. Comparisons of the antifungal activities of cadinane skeletal sesquiterpenoids from Taiwania (Taiwania cryptomerioides Hayata) heartwood. Holzforschung 54, 241-245.

Chang, S.T., Chen, P.F., Chang, S.C., 2001. Antibacterial activity of leaf essential oils and components from Cinnamomum osmophloeum. J. Ethnopharmacol. 77, 123-127.

Chang, S.T., Cheng, S.S., 2002. Antitermitic activity of leaf essential oils and components from Cinnamomum osmophloeum. J. Agric. Food Chem. 50, 1389-1392.

Cheng, S.S., Liu, J.Y., Tsai, K.H., Chen, W.J., Chang, S.T., 2004. Chemical composition and mosquito larvicidal activity of essential oils from leaves of different Cinnamomum osmophloeum provenances. J. Agric. Food Chem. 52, 4395-4400.

Cheng, S.S., Liu, J.Y., Hsui, Y.R., Chang, S.T., 2006. Chemical polymorphism and antifungal activity of essential oils from leaves of different provenances of indigenous cinnamon (Cinnamomum osmophloeum). Bioresour. Technol. 97, 306-312.

Kim, H.K., Kim, J.R., Ahn, Y.J., 2003. Acaricidal activity of clove bud oil compounds against Dermatophagoides farinae and Dermatophagoides pteronyssinus (Acari: Pyroglyphidae). J. Agric. Food Chem. 51, 885889.

Kim, H.K., Kim, J.R., Ahn, Y.J., 2004. Acaricidal activity of cinnamaldehyde and its congeners against Tyrophagus putrescentiae (Acari: Acaridae). J. Stored Prod. Res. 40, 55-63.

Kondo, R., Imamura, H., 1986. Antifungal compounds in heartwood extractives of hinoki (Chamaecyparis obtusa Endl.). Mokuzai Gakkaishi 32, 213-217.

Lee, H.C., Cheng, S.S., Chang, S.T., 2005. Antifungal property of the essential oils and their constituents from Cinnamomum osmophloeum leaf against tree pathogenic fungi. J. Sci. Food Agric. 85, 2047-2053.

Morita, S.I., Hidaka, T., Yatagai, M., 1997. Antifungal compounds of the extractives of Yakusugi (Crypromeria japonica D. Don). Wood Preserv. 23, 11-19.

Rudman, P., 1965. The causes of natural durability in timber XVIII. Further notes on the fungi toxicity of wood extractives. Holzforschung $19,57-58$ 
Schultz, T.P., Nicholas, D.D., 2000. Naturally durable heartwood: evidence for a proposed dual defensive function of the extractives. Phytochemistry 54, 47-52.

Wang, S.Y., Chen, P.F., Chang, S.T., 2005a. Antifungal activities of essential oils and their constituents from indigenous cinnamon (Cinnamomum osmophloeum) leaves against wood decay fungi. Bioresour. Technol. 96, 813-818.

Wang, S.Y., Wu, C.L., Chu, F.H., Chien, S.C., Kuo, Y.H., Shyur, L.F., Chang, S.T., 2005b. Chemical composition and antifungal activity of essential oil from Chamaecyparis formosensis wood. Holzforschung 59, 295-299.
Wedge, D.E., Galindo, J.C.G., Macias, F.A., 2000. Fungicidal activity of natural and synthetic sesquiterpene lactone analogs. Phytochemistry $53,747-757$.

Wu, C.L., Chien, S.C., Wang, S.Y., Ku, Y.H., Chang, S.T., 2005. Structure-activity relationships of cadinane-type sesquiterpene derivatives against wood-decay fungi. Holzforschung 59, 620-627.

Yen, T.B., Chang, S.T., 2008. Synergistic effects of cinnamaldehyde in combination with eugenol against wood decay fungi. Bioresour. Technol. 99, 232-236. 